\title{
Factors Affecting the Effectiveness of Advertising in the Current Scenario "Advertising Factors are Immune to Business which Aspire to Inspire before You Expire"
}

\author{
D. Lakshmanan ${ }^{1}$, Dr. S. Rabiyathul Basariya ${ }^{2}$ \\ ${ }^{1}$ Research Scholar, Department of Management Studies, Bharath University \\ ${ }^{2}$ Associate Professor, Department of Commerce and Business Administration, Bharath University
}

\begin{abstract}
Due to the increasing development of business, advertising that is considered as one of its basic tools, has grown in importance. Meanwhile, factors that affect creating positive attitude towards advertising are important concepts which have attracted much attention. It is also an important issue for companies that their advertisements have effective and influential components. Positive attitude towards advertisement refers to overall feelings and assessment of people about advertisement .Television is considered as a mass media with larger audience comparing other advertisement media due to its unique characteristics in sending video messages to the farthest corners of the world; and it is of great importance because it has all the three influential components including sound, image and movement. Therefore, the present study aims to investigate and identify the factors affecting creating a positive attitude of audiences towards television advertising. In this study, "positive attitude towards advertisement" is dependent variable and affecting factors as independent variables include "explaining standards ", "announcing superior marks ","religious factors in advertisement", " transparency of advertisement", "trust building in advertisement","foregrounding advertisement "and" non-irritant advertisement". This research is a descriptive case study and the data is collected through a questionnaire by the researcher. And the results of this study emphasize the need for effective and influential factors in managing positive attitude of the audience towards television advertising. The present study's outcome leads to introducing a new model for measuring audiences' positive attitude towards advertisement of the national media of television.
\end{abstract}

Keywords: Advertisement, Factors Affecting Effectiveness of Advertisement, Impact of Advertisement

\section{Introduction}

Advertising is an instrument of information and persuasion. As per one definition "Advertising is the non -personal communication of information usually paid for and usually persuasive in nature about products, services or ideas by identified sponsors through the various media" (Bovee, 2012)1.The informative role of advertising consists in provision of information about products, features, functions, specifications and prices to prospective buyers. Due to ignorance of advertising, they may purchase an inferior product, pay higher prices, or worse still, may not even know the variety of products that exist. This increases the short-run propensity to consume by informing buyers of the various bargains available. Besides, it is also true that consumer spending declines when the normal advertising flow is cut-off.

By advertising the goods, a manufacturer comes in direct touch with the consumers. Banking upon this information, the manufacturer can directly sell to the customers. The number of middlemen, whose margins increase the price for the consumers, is consequently reduced.

Advertising ensures better and improved quality of goods to consumers at cheaper rates. Since advertised goods promise a certain quality which has to be maintained and further mass advertised goods are produced and distributed in large quantities, thus reducing the production cost per unit (due to economies of scale).
Goods are generally advertised with brand names. When an advertisement appears with a brand name, it imprints an image of the product in minds of the consumer. If the use of the advertised product confirms their expectations, a repeat order is expected and the product will earn a favourable image and good reputation. Thus, the manufacturer is prompted to maintain and if possible, improve the brand quality so that the confidence of consumers is maintained. Else, the brand will lose market share.

Advertising creates the desire to possess better and newer items by educating the buyers about better life-style. Advertising gives a direct stimulus to consumer which in turn prompts the producer to produce more and better quality. On the other hand, advertising acts as a mirror that shows the country's way of life. It is in fact a running commentary of the way people live and behave. Advertising and selling have played an important part in expanding the economic system by stimulating consumers into buying more. Advertising makes people work harder than they otherwise would. This has had the effect of raising the aggregate level of the economy. In the long run, advertising has probably played a major part in making people favourably disposed towards high levels of consumption and in creating new products and ideas. Thus, advertising also increases the employment levels, directly and indirectly. Advertising reduces the risk of innovation. The cost of innovation can be more than recovered by the sales which advertisements may generate and encourage manufacturers to undertake research and development. The revenue 


\section{International Journal of Science and Research (IJSR) \\ ISSN (Online): 2319-7064}

Index Copernicus Value (2015): 78.96 | Impact Factor (2015): 6.391

through subscriptions is quite inadequate to support the publication of newspapers, magazines or TV channels. Advertising revenues, in fact, provide a greater support to viable functioning of these media.

Further, advertising encourages competition and subsequently firms compete with each other to provide the best products and services to create and sustain brand loyalty. This also creates price competition. But while dispensing its role as a dream merchant, advertising has also been in controversy because of the many ills that it brings to society. It is accused of encouraging materialism and consumption, of stereotyping, of causing us to purchase items for which we have no need, of taking advantage of children, of manipulating our behaviour, using sex to sell, and generally contributing to the downfall of our social system. Advertising does not function in a vacuum but in a market environment where several forces like consumer needs, business interests and government regulations are at work. It is a powerful force in terms of its persuasiveness and functions a critical social role. Moreover, the high visibility and pervasiveness, it generates criticism and controversy. Much of this controversy springs from the fact that advertising is used more as a persuasive communication tool thereby creating serious impact on the tastes, values and lifestyles of society.

\section{Literature Review}

According to Burton (2011), it is easier to accomplish objectives at the lower level of the pyramid than the ones at the top. The percentage of prospective customers also declines as you move up the pyramid. The communicator must therefore build conviction among the target audience so as to take the final step of purchasing the product. Advertising therefore involves a sequence whereby the prospect is moved through a series of stages in succession from unawareness to the purchase of the product.

According to Czinkota and Kotabe (2012), advertising is an indirect contact with the customer. It is only one half of a dialogue. If it does not respond to customer needs, it will probably fail no matter how creative it is. Armstrong (2014), is to identify customer benefits that can be used as advertising appeals. This is because people will react only if they believe that they will benefit from doing so. Advertising appeals should have three characteristics; meaningful, believable and distinctive. Meaningful means that they should point out the benefits that make the product more desirable or interesting to the consumer. Believable the consumers must believe that the product or service will deliver the promised benefits. Lastly, distinctive means that they should tell how the product is better than competing brands.

\section{Significance and Necessity of the Study}

Today, manufacturing and delivering goods alone is not enough because developing activities have changed and attracting customers in a competitive environment is necessary. Advertising is considered part of a successful marketing and successful companies, particularly in exports field, in addition to improving the quality of their products, follow designing and using dynamic media with influential factors affecting the audience. With technological developments in the last century, the media have had more and more penetration in families' living atmosphere. This penetration has now reached a point that even if we ignore the new generation who are always online, we see that the time people spend on paying attention to media is more than the time they spend working. Almost two-thirds of our waking hours in the day, about ten and half hours, is spent with the media (Humayun, 2007). However, with the arrival of new media and attracting a larger audience, television is facing with the risk of losing its share in advertising market.

One of the main reasons for this decline is the lack of measures for assessing influence of advertisements through which advertisers can assess the effectiveness of their advertisements and have better planning. With respect to demand of advertisers for precise measurement of advertisements' impact, television executives should seek to identify and measure impact of various advertisement factors on attitude of their audiences or customers to maintain and increase their share of the advertising market. Obviously the creators of television advertisements should benefit models, techniques, and a variety of attractions in structure of the television ads in order to attract attention, create interest, motivate and lead the audience to buy so that they manage their audiences' tendency since there is a decision making process in shopping practice that results from audiences attitude towards advertisement by which he/she decides on purchasing a product or service. Therefore, in this respect identifying affective and influential factors on management of audiences' positive attitude seems very important.

\section{Objectives of the Study}

The Primary objective: The present study attempts to examine the factors affceting the effectiveness of advertising.

The Secondary objectives:

- To identify various factors for assessing the effectiveness of advertisements.

- To understand the influence of advertisements ${ }^{\text {ee }}$ features on the effectiveness.

- To explore the impact of affecting factors towards the effectiveness of advertisements.

\section{Factors Affecting the Effectiveness of Advertising}

The type of selling message: It is more of the advertising requirements that decide the appropriate choice. The advertisers may be interested in appealing the prospects by colour advertisements. In that case, magazine, film, television, bill- boards, bulletin boards serve the purpose. If the timeliness is the greater concern, one should go in for news-paper, radio, posters. If demonstration is needed there is nothing like television and screen media. If new product is to be introduced, promotional advertising is most welcome. 


\section{International Journal of Science and Research (IJSR) \\ ISSN (Online): 2319-7064}

Index Copernicus Value (2015): 78.96 | Impact Factor (2015): 6.391

The budget available: A manufacturer may have a very colourful and bold plan of advertising. He may be dreaming of advertising on a national television net-work and films. If budget does not allow, then he is to be happy with a low budget media like his news-paper and outdoor advertising.Instead of colour print in magazine, he may be forced to go in for black and white. Thus, it is the resource constraints that decide the choice.

Competitive advertising: A shrewd advertiser is one who studies carefully the moves of his competitor or competitors as to the media selected and the pattern of expenditure portrayed. Meticulous evaluation of media strategy and advertising budget paves way for better choice. It is because, whenever a rival spends heavily on a particular medium or media and has been successful, it is the outcome of his experience and tactics. However, blind copying should be misleading and disastrous.

Media and the celebrity availability: The problem of media availability is of much relevance because; all the required media may not be available at the opportune time. This is particularly true in case of media like radio and television; so is the case with screen medium. Thus, nonavailability of a medium or a media poses a new challenge to the media planners and the people advertising industry. It is basically an external limit than the internal constraint. Effectiveness of a celebrity in product advertisement is a function of celebrity perceived expertise, trustworthiness, attractiveness and credibility among the target audience. This implies that these four characteristics make celebrity unique and are crucial to advertising effectiveness, where celebrities are used. This framework identifies four critical factors for achieving successful celebrity endorsement.

Frequency- Frequency basically means average number of time the receivers or individual is exposed to the media vehicle in specified period of time. Objectives of a media plan often call for some arrangement of reach and frequency. Media planners want the highest reach possible because that means advertisement has been exposed to most of the people, which should lead to more customer loyalty, brand awareness, sales, and so on. The frequency of advertisement exposure to the target market depends upon the amount of reminders required to have sustaining benefaction from the target customers.

Market threats: Some Internal/External or uncontrollable factors may pose as a threat to the organization, and a change in media strategy is instantly needed. For example, a sudden ban on outdoor media like uni poles may insist a media planner to shift to an electronic media like T.V Commercials. This alteration in media strategy for him will gain an edge from the competitor.

Location and Time: Location-based advertising is regarded as one of the most interesting opportunities mobile commerce has to offer, because of its impact on the perceived informational utility. Various studies have empirically verified an increase in advertisement effectiveness through spatial advertising. In this research "ad localization" is considered as sending information to consumers based on their location, in order to convince them to visit a physical store. Furthermore, consumer behaviourdriven theory points out to the interdependence of time and location. Targeting prospects at the right time and place actually implies minimum perceived effort for the prospect to buy the advertised product for which he is interested. Therefore, time and location were put under the umbrella of perceived effort to buy the advertised product. Thus, advertisements lead to more positive attitudes towards the advertisement and the brand and to more positive purchase intentions when the perceived effort to buy the advertised product is low.

Interactivity: Interactive elements of a mobile ad attempt to elicit cognitive response by allowing the viewer to look for more information via the mobile device. By providing interactivity, the advertiser is attempting to increase viewer involvement by creating two-way communication in real time, instead of the usual more traditional one-way types of advertising accomplish. Studies had shown that the level of interactivity is positively associated with ad and product attitudes.

Incentive: Individuals are interested in deriving some monetary benefit from direct marketing programs. Nine out of ten (86 percent) of the respondents to a Nokia-sponsored survey, conducted by HPI Research Group, on mobile marketing agreed that there should be a trade-off for accepting ads on their mobile devices. Research proposes that price discounts (an incentive type as it provides a temporary reduction of the list price of the product) are particularly effective in inducing several outcomes such as purchase acceleration and product trial.

Ad Source or Advertiser credibility: The term ,source credibility $^{\text {ee }}$ is repeatedly used to refer to traits of the communicator including expertise, trustworthiness, attractiveness, and power. Researches had found that credibility strongly influenced attitude towards advertiser and attitude towards advertiser was the most important predictor of attitude towards the ad. Corporate credibility is defined as "the extent to which consumers believe that a firm can design and deliver products and services that satisfy customer needs and wants" and has been found to have direct, positive effects on attitude towards the ad, attitude towards the brand, and purchase intent.

Appeal: Message appeals are usually divided into rational appeals and emotional appeals. Rational appeals are typically based on factual information and focus on product attributes. Emotional appeals on the other hand typically intend to create positive emotions and develop a brand personality. Emotional appeal has been found to be most effective when brand response involvement and advertising message involvement are low, whereas informative appeal is found to be relatively more effective when customers are highly involved with the brand and advertisement.

Product Involvement: In light of this review, there is a need for comparative research that will explore whether mobile users react differently to diverse types of products. As argues, "it is likely that the relative effect of cognition versus affect varies... across objects (e.g., perfumes vs. mutual funds)". According to the FCB Grid products differ 


\section{International Journal of Science and Research (IJSR) \\ ISSN (Online): 2319-7064}

Index Copernicus Value (2015): 78.96 | Impact Factor (2015): 6.391

in their "feel or think" nature. When individuals base their purchase decision mainly on how they feel about the product, then the product is characterized as "feel". On the other hand, when purchase decision is based mainly on thoughts, then the product is characterized as "think". As argue, the degree to which consumers process advertising communications and they react to the message in an active or passive way depends on theirinvolvement to the product.

Ad Size: Individuals will have to go through the message before determining if it is of any value. This process places a cognitive burden on them and probably affects their message involvement and elaboration. In the Web the number of words in a banner advertisement has a negative coefficient, suggesting that lengthy messages reduce direct response. This leads to the assumption that long messages involve paying close attention, which users are rarely inclined to do.

Language: Considerable work has been done in the words chosen for verbal commercial communication. Several studies in print advertising have illustrated that a variety of different language/sentence combinations of writing were more acceptable than other combinations. Current mobile advertising practice has adopted the use of personal pronouns and imperative for achieving ad personalization by assuming that personal and active language will lead to better campaign results. In parallel, by examining several advertising text messages the authors inferred that the use of acronyms was heavily employed probably to produce desired reader effects through the use of a colourful language.

Content Concreteness - Abstractness: An additional goal of the present study was to test if abstract or concrete type of information is preferred by advertisements readers. It is reasoned that communication that embodies precise and concrete information will present better outcomes than abstract information. Concrete advertisements contain more details than abstract advertisements and probably could be more influential because it would be easier to recall and visualize the specific details.

Attitude towards advertising in general: The study of attitude towards advertising in general may be especially significant because it influences attitudes towards the ad, an important antecedent of brand attitudes. This finding also applies in interactive media such as the Web. According to, general attitude towards advertising was also found to have a significant positive effect on banner Ad and attitude towards the brand. also found that consumers generally have negative attitudes towards mobile advertising unless they have specifically consented to receive mobile advertisements.

\section{Conclusion}

Advertising appeals aim to influence the way consumers view themselves and how buying certain products can prove to be beneficial to them. The message conveyed through advertising appeals, influences the purchasing decisions of consumers. The above mentioned factors are drastically affecting the effectiveness of advertisement in the current scenario. The producers and the competitors should identify these factors vividly to render inevitable advertisements effectively for boosting up the product in the competitive market.

\section{References}

[1] Armstrong, E. 2014. How Clicks (Almost) Killed Display Advertising: A Brief History. [online] Whitehorse. Available

at: http://www.whitehorse.com/blog/displayadvertisinggame-theory.aspx - How Clicks (Almost) Killed Display Advertising: A Brief History [Accessed in May 2015].

[2] Burton (2011), Advertising Effectiveness: Understanding the value of a Social Media Impression.

[3] Czinkota and Kotabe (2012). The effect of competitive advertising interference on sales of package goods. Journal of Marketing Research, 45(2), 211-225.

[4] Denham, B. E. (2004). Toward an explication of media enjoyment: The synergy of social norms, viewing situations, and program content. Communication Theory, 14(4), 370-387.

[5] Gerard, J, T., 2009 b. Generalisations about Advertising Effectiveness in Markets. Journal of Advertising Research, 4:242-243

[6] Gibs, J. \& Bruich, S., 2010. Advertising Effectiveness: Understanding the value of a Social Media Impression, [e-journal] 1(1),

[7] Neill, S. 2007. Achieving Adaptive Ends Through Equivocality: A Study of Organizational Antecedents and Consequences, [e-journal], 306 -307.

[8] Silva, R.V. \& Alwi, S.F.S. (2006). Cognitive, affective attributes and cognitive, behavioural responses in retail corporate branding, Journal of Product \& Brand Management, 15(5):293-305.

[9] Temkin, B.D. 2008b. Engage Gen Y online with Immediacy

http://www.forester.com/Research/Document /Excerpt/0,7211,43647,00.html. 